\title{
Retrospectiva de una investigación doctoral: inquietudes iniciales, operacionalización e (in)conclusiones
}

\author{
VERÓNICA PAULA GÓMEZ IIBICRIT - SECRIT / CONICET - CEDINTEL, Argentina \\ ORCID 0000-0001-7347-3683 \\ veronicagomez@conicet.gov.ar
}

\section{Resumen}

En este artículo se reseña la trayectoria de la tesis doctoral titulada «Domicilios de la literatura digital: de la idea de Nación a la de interzona» defendida en agosto de 2020 para obtener el título de Doctora en Humanidades con mención en Letras (FHUC-UNL). En este trabajo expongo el problema de investigación, las hipótesis y objetivos de la tesis, la organización de la misma en partes y capítulos, las decisiones metodológicas adoptadas y el análisis que de todo ello se deriva. Al mismo tiempo, tal exposición se acompaña de ciertos hallazgos que se produjeron de forma fortuita a lo largo del trabajo, algunos obstáculos que hubo que sortear y aspectos inconclusos que motivan futuros proyectos e investigaciones individuales y colectivos. El objetivo del trabajo que presento aquí es acercar al lector a la trayectoria de construcción y escritura de una tesis, con todos los desvíos y replanteamientos que ello supone, al tiempo que pretendo divulgar los resultados de la misma.

Palabras clave: tesis / doctorado / investigación / literatura digital / teoría política

\section{Retrospective of a doctoral research: initial concerns, operationalization and (in)conclusions}

Abstract

This article reviews the trajectory of the doctoral thesis entitled «Electronic literature locations: from the idea of Nation to that of interzone in ELO (Electronic Literature Organization)», defended in August 2020 to obtain the title of Ph.D. in Humanities with a mention in Letters (FHUC-UNL). In this work, I present the research question, the hypotheses and objectives of the thesis, its organization in parts and chapters, the methodological decisions adopted and the analysis that derives from all of this. At the same time, such an exhibition is accompanied by certain findings that occurred fortuitously throughout the work, some obstacles that had to be overcome, and unfinished aspects that motivate future individual and collective projects and research. The objective of the work that I present here is to bring the reader closer to the trajectory of construction and writing of a thesis, with all the detours and rethinking that this implies, while I intend to disclose the results of the thesis.

Key words: tesis / Ph.D / research / electronic literature / political theory

Recibido: 15/5/2021. Aceptado: 3/7/2021

Para citar este artículo: Gómez, V.P. (2021). Retrospectiva de una investigación doctoral: inquietudes iniciales, operacionalización e (in)conclusiones. El taco en la brea, (14) (junio-noviembre). Santa Fe, Argentina: UNL. e0045 DOI: 10.14409/tb.2021.14.eoo45 


\section{Toma 1. La pregunta por el lugar}

Durante casi tres años me dediqué con ahínco a escribir mi tesis doctoral,' en medio de una ajetreada vida académica que incluyó dos estancias en el extranjero, la publicación de artículos con resultados parciales, la adaptación a un contexto nuevo de trabajo, la participación en reuniones académicas en español, pero también en inglés, en francés, en italiano, lenguas que multiplicaron las dificultades y desafiaron mi capacidad explicativa para volver fácil y accesible lo que parecía un enredo inicial, entre tantas otras cosas que componen la vida de una tesista. Pero mentiría si dijera que mi tesis se reduce a esa tríada de años frenéticos y hermosos de escritura afanosa. He aquí una retrospectiva del proceso que se remonta, tal vez, a la mismísima niñez.

Esta hoja de ruta comienza por una pregunta constante y, a primera vista, sencilla sobre la relación entre literatura y lugar. La inquietud inicial es difícil de ceñir en el tiempo. Primeramente, se vincula, como cualquier pregunta que nos apasiona, con la historia personal: una vida de desplazamientos reiterados y necesarios de enormes distancias, y palabras que explicaban los afectos divididos, las casas lejanas, las bibliotecas partidas en dos, la soledad de los tránsitos. No ser de ninguna parte o ser de todas partes fue una premisa que marcó a fuego la pregunta por el lugar desde la temprana infancia. Dar explicaciones de ello estampó la necesidad de poner en palabras, con distintos acentos, con distintas cadencias por qué no era posible dar una respuesta unívoca. La dificultad de la niña migrante que se hace lingüista.

Esa pregunta se profundizó durante los años de tránsito por el grado. La lista de materias vinculadas a literaturas nacionales me causaba inquietud. ¿Por qué hablábamos de literatura francesa o inglesa? ¿Por qué era tan importante conocer medianamente el italiano para ser admitidos en un seminario sobre la Divina Commedia? ¿Con qué traducciones contábamos? ¿Qué entendíamos y qué perdíamos cuando se trataba de literatura japonesa? ¿Qué hacía falta para que las novelas novatas de algunos de mis compañeros se transformaran luego en las obras salientes de la literatura argentina joven? Esos cuestionamientos eran vagos y ya que se daba por hecho que ese era el estado de cosas en la carrera de Letras - por algo había planes estudio, traducciones, lenguas nacionales y libros que leer-, me sumergí en cierta obediencia a conocer esas literaturas dejando subsumido el cuestionamiento sobre su procedencia nacional.

Al encarar la escritura de la tesis doctoral, la pregunta que se había sostenido en el tiempo vital y profesional había también madurado sus términos luego de haber observado y estudiado la manera en que la literatura se domicilia en la idea política de Nación, dejando en los márgenes otros desarrollos y cosmovisiones. ${ }^{2}$ Estas observaciones comprendieron encuentros de diverso tipo con otros saberes - la sociología, la ciencia política, la filosofía, la sociolingüística- y con la forma en que, crecientemente, las tecnologías y el soporte digital pasaron a colonizar nuestras vidas. Así, el lector de mi tesis se encuentra, primero, con reflexiones sobre un objeto que probablemente le es conocido y cercano, los libros impresos en lenguas nacionales, y sobre una idea política reconocible, la Nación, y poco a poco se adentrará en producciones que se vinculan a la literatura experimental, particularmente, la literatura digital, en la que las materialidades de la letra se escabullen ante cualquier linealidad, y en la que la imagen contemporánea de la superposición y el conceptualismo dan cuenta de un nuevo domicilio político que intenté identificar y nombrar a partir de la idea de interzona (Gómez, 2021), sobre la que hablaré más adelante.

Como corolario de un largo proceso de lectura, conversación y escritura, me hallaba por fin ante una primera premisa «operacionalizada», es decir, la aseveración que hizo de las intuiciones 
iniciales una traducción en términos teóricos. Así, mi trabajo indaga en torno de la relación entre literatura y lugar, en tanto domicilio político de la escritura (Derrida, 1997). Con domicilio político de la escritura, sigo la enseñanza de Derrida al señalar que el proceso de domiciliación no es solo de corte topológico, sino también nomológico, es decir, no afecta solo el lugar (topos) sino la ley (nómos). Se trata, entonces, de una función «toponomológica» de consignación, entendida no solo como «el hecho de asignar una residencia (...) o en un lugar y sobre un soporte, sino también aquí el acto de consignar reuniendo los signos» (1997:11. Énfasis en el original). Los cuerpos en los que se inscriben las impresiones, sus desplazamientos significantes y las excepciones a la ley instituida por la hegemonía de un mundo ideativo como el de la Nación forman parte sustancial de mi tesis, para explicar las formas de partida que operan en la relación entre literatura y lugar. Ese vínculo ha sufrido numerosas transformaciones a lo largo del tiempo debido a que en él se consignan importantes aspectos geopolíticos y, consecuentemente, disputas, alianzas, conflictos y emergencias de variada índole que han afectado los movimientos en el campo intelectual y de las artes, al tiempo que han dado espacio a determinadas políticas sobre las territorialidades, las tecnologías y los lenguajes. Así, las intervenciones de la literatura en particular, y de las artes en general, permiten la apropiación crítica del lugar de pertenencia, mientras que sus domicilios se sirven de ellas para desenvolverse en sus sociedades bajo determinada inventiva de época.

Esta operacionalización vino de la mano de un encuentro fortuito con una manera particular de formular el problema en los términos de una ecuación de partida y una de llegada que, como veremos en el próximo apartado, me permitió decir lo que al principio se encontraba disperso y encriptado en hallazgos sueltos que iban apareciendo en el curso de la investigación.

\section{Toma 2. La epifanía de las ecuaciones}

Durante un largo periodo, estuve en busca de una manera medianamente sintética de graficar lo que quería decir. Eso me permitiría ordenar ideas dispersas, como mencionaba anteriormente. Fue recién en una clase de Microeconomía, ${ }^{3}$ mientras una profesora explicaba la función de oferta y demanda, cuando tuve una especie de revelación. Era posible realizar un movimiento de imitación como hace una parte de la crítica de la sociología de la cultura que piensa el objeto literario en el marco de una bolsa de valores (Casanova, 2001) que supone la tenencia o carencia de un determinado capital. Del mismo modo, en un paralelo con la ciencia económica, se expresa la relación entre literatura y lugar mediante la expresión de una ecuación de partida y una de llegada, con variaciones en cada uno de sus determinantes — territorialidades, tecnologías y lenguajes.

LITERATURA Y LUGAR = TERRITORIALIDADES + TECNOLOGÍAS + LENGUAJES

Dentro de los profusos cambios que podemos vislumbrar en torno a esta relación mencionada entre literatura y lugar, en la tesis me dediqué a estudiar uno en particular, que afecta a la domiciliación contemporánea. Así, partí de la idea de Nación como forma consolidada e institucionalizada en la que se han domiciliado hegemónicamente las producciones literarias impresas en lengua nacional de por lo menos las últimas tres centurias en Occidente, para luego analizar el proceso de transformación que se está produciendo actualmente ante la emergencia de la literatura digital (Hayles, 2008), que requeriría otra idea vector en la que inscribirse. 
A partir del gráfico de base precedente, en donde los términos están expresados de modo abstracto, se sostiene una ecuación de partida que tiene que ver con la hegemonía de la idea de Nación (Anderson, 2006; Balibar, 1991; Gellner, 2001) en tanto residencia de la literatura impresa y escrita en lengua nacional. La ecuación se presenta como la resultante de al menos tres determinantes relativos y relacionales: una soberanía (Portinaro, 2003) ligada al territorio estatal en donde rige la dominación legal-racional weberiana (Weber, 2015), una forma tecnológica de reproducción masiva, la imprenta (Febvre y Martin, 1962), y una lengua nacional homogeneizadora (Goldchluck, 2013). Estos determinantes permitieron el nacimiento, la consolidación y la expansión de lo que conocemos como literatura impresa nacional. La función anterior podría graficarse como sigue:

LITERATURA E IDEA DE NACIÓN = TERRITORIO ESTATAL SOBERANO + SOPORTE IMPRESO + LENGUA NACIONAL

Este desglose de una idea aún hegemónica convive en la actualidad con una ecuación cuyos componentes son los emergentes de la cultura visual global (Darley, 200o). Así, se afirma que los vínculos entre la literatura y su domicilio nacional se ven corroídos, dando lugar a la hipótesis central de la tesis: existen cambios de función en la ecuación propuesta dada la modificación de cada uno de sus factores por condicionamientos de producción y consumo propios de la literatura digital (Hayles, 2008) que se trasladan ahora al ciber-espacio bajo otra idea vector, ya no nacional, que reconfigura la organización geopolítica de ese mapa de fuerzas en pugna (Casanova, 2001) en un contexto de modernidad desbordada (Appadurai, 2001).

A partir de la hipótesis general, expresada en el párrafo anterior, esta investigación propone la idea alternativa de interzona (Gómez, 2015, 2021) que permite pensar la domiciliación de la literatura dados los términos que componen la función ideativa de lugar que sostiene las tecnopoéticas (Kozak, 2015), en particular, y la circulación y el consumo de bienes culturales en general, surgida a partir de la hegemonía tecnodigital global (Romano Sued, 2013). Esta nueva ecuación podría expresarse gráficamente como sigue:

LITERATURA DIGITAL

E IDEA DE INTERZONA $=\quad$ TERRITORIALIDADES
CIBERESPACIALES
LENGUAJES

INTER/TRANSMEDIALES

Así, las producciones de literatura digital que se realizan exclusivamente para y mediante computadoras conectadas en la mayor parte de los casos a internet (Rettberg, 2012) suponen modos alternativos de diseño y abordaje del campo cultural (Bourdieu, 2005), que dan lugar a la pregunta de investigación: ¿qué transformaciones operan en el vínculo entre literatura y lugar, cuando la idea de Nación, tradicionalmente domicilio geopolítico de la literatura impresa escrita en lengua nacional, se halla expuesta a la emergencia de la literatura digital, producida y consumida en el ciberespacio desterritorializado, en entornos virtuales multilingües e intermediales? Para dar una respuesta concreta a esta pregunta recurrí al análisis de un caso pionero: Electronic Literature Organization (ELO) (http://www.eliterature.org/). Me propuse, entonces, como objetivo general, explorar la transformación del domicilio político de la literatura: de la idea de Nación como residencia dominante de la literatura impresa nacional a la de interzona, resultante de la emergencia de la literatura digital, sobre la base del estudio de un caso (ELO). A partir de todo 
lo anterior, la estructura de la tesis podría graficarse, a grandes rasgos, con el siguiente cuadro ilustrativo:

\begin{tabular}{|c|c|c|c|c|c|c|}
\hline \multirow[t]{2}{*}{$\begin{array}{l}\text { LITERATURA IMPRESA } \\
\text { E IDEA DE NACIÓN }\end{array}$} & $=$ & $\begin{array}{c}\text { TERRITORIO ESTATAL } \\
\text { SOBERANO }\end{array}$ & + & SOPORTE IMPRESO & + & LENGUA NACIONAL \\
\hline & & $\downarrow$ & & $\downarrow$ & & $\downarrow$ \\
\hline \multirow{4}{*}{$\begin{array}{l}\text { LITERATURA DIGITAL } \\
\text { E IDEA DE INTERZONA }\end{array}$} & $=$ & TERRITORIALIDADES & $t$ & SOPORTF DIGITAI & + & LENGUAJES \\
\hline & & CIBERESPACIALES & + & SUPURIE DIGIIAL & & INTER/TRANSMEDIALES \\
\hline & & $\downarrow$ & & $\downarrow$ & & $\downarrow$ \\
\hline & & $\begin{array}{l}\text { PRIMERA PARTE: } \\
\text { TERRITORIALIDADES }\end{array}$ & & $\begin{array}{l}\text { SEGUNDA PARTE: } \\
\text { TECNOLOGÍAS }\end{array}$ & & $\begin{array}{l}\text { TERCERA PARTE: } \\
\text { LENGUAJES }\end{array}$ \\
\hline
\end{tabular}

De la hipótesis central, se desprenden tres hipótesis subsidiarias, tendientes a dar cuenta del proceso de transformación de cada uno de los factores aludidos en la ecuación general - territorialidades, tecnologías, lenguajes - que a su vez responden a cada una de las partes de la tesis en sí misma tituladas de manera homónima.

A continuación, presento un breve resumen de las partes y los capítulos que componen la tesis. Una vez concluida, el trabajo se orientó a constituir un aporte a esta nueva ecuación de lugar y proponer la idea de interzona como alternativa a la de Nación.

\section{Toma 3. La organización astuta de una tesis}

En primer lugar, fue elemental armar un índice tentativo de capítulos y en este caso partes, lo cual supuso una serie de escollos que intenté sortear. Por un lado, renuncié a algunas cuestiones que no eran factibles de ser estudiadas aquí y también me vi obligada a incluir otras que no tenía previstas en un principio. De allí que hablemos de un diseño cualitativo flexible en esta tesis que presenta un diálogo fluido entre teoría y estudio de campo.

En la Primera Parte: Territorialidades, se trabajó sobre la hipótesis de que la literatura tradicionalmente inscripta como bien cultural en el marco de un territorio soberano (Portinaro, 2003) se traslada a territorialidades nómades ciberespaciales (Maffesoli, 2006; Beiguelman y La Ferla, 2011), lo que supone una geopolítica en términos glocales, desbordando la vinculación con la referencia nacional bajo la idea de redes imaginadas (Chun, 2011). Esta hipótesis intenta responder a un cuestionamiento en torno a la domiciliación política dominante, la Nación, como vector ideativo de la organización del mundo circundante. Observamos, por lo tanto, la naturalización de esa idea que dio lugar a las fronteras y los espacios de una imaginación común con mayor o menor fortuna según el caso. La demarcación de un territorio no significa solo un hecho material, sino, sobre todo, uno de corte político que afecta las formas en las que el arte y, en particular, la literatura se define y se adecúa. De allí que esta parte responda a uno de los objetivos específicos de la tesis: describir el proceso de transformación progresiva del territorio soberano del Estado-Nación hacia territorialidades nómades propias de la organización geopolítica del ciber-espacio.

Esta primera parte está dividida en tres capítulos, dos dedicados a la exposición del marco teórico y el estado de la cuestión, y un tercero de análisis del caso ELO como plataforma en la que aparece cierto funcionamiento de agentes y prácticas de campo, como explicaré más adelante. 
El «CAPÍTULO 1. Territorios de la literatura» introduce el problema a partir de la exposición de un extenso marco teórico de base sobre la Nación, los nacionalismos y la imaginación nacional, así como también la diferencia fundamental y ambivalente entre Estado, como eje burocrático, y Nación, como idea fundante de una imaginación común. Indagamos acerca de lo que significa «narrar la Nación» en la medida en que se desarrollan dos formas de difusión masiva de la lengua nacional: la novela y el periódico, junto con instituciones alfabetizadoras, como la escuela y las bibliotecas públicas. Pero estas expresiones teóricas se enmarcan idealmente en una modernidad europea y poco a poco comienzan a resquebrajarse vista la heterogeneidad de un mundo muy diverso hacia donde se expanden. Dada una serie de profundas transformaciones y desestabilizaciones en los discursos modernos, la segunda parte de este capítulo se enfoca en desarrollos tendientes a explicar la imposibilidad de una identidad de orden «nacional» $\mathrm{y}$ «homogénea» en gran parte de los territorios de nuestro planeta que son considerados hoy «naciones» y que producen «literatura» impresa en lengua «nacional». En suma, este capítulo propone, primeramente, desarrollar lineamientos teóricos sobre la idea de Nación y sus conceptos vinculados, y posteriormente, ponerlos en tensión con desarrollos críticos acerca de cierto eurocentrismo conceptual.

En el «CAPÍTULO 2. El ciberespacio como interzona», se expone la relación entre la literatura digital y el lugar, introduciendo las razones por las que una literatura de ese tipo no se adecúa a criterios de orden nacional desarrollados en el Capítulo 1 ni para producirse ni para consumirse. Sin embargo, la pregunta por el lugar no cesa. Es justamente el hecho de que la literatura digital se halle alojada en el ciber-espacio lo que nos obliga a pensar en la paradójica territorialidad de lo aparentemente desterritorializado, sus límites, sus contornos, sus intercambios. Luego de una larga exposición de argumentos que ocupan la primera parte del capítulo en torno del problema acerca de la nomenclatura de lugar propia de una literatura difícil de asir, propongo la noción de interzona como posibilitadora de una cierta cartografía que permite posicionar de manera móvil y fluida estas producciones. Se apela brevemente a la historia del concepto de interzona y las formas en que permiten postular una descripción del campo y un análisis posterior de las obras en la segunda y tercera partes de la tesis.

Por último, esta primera parte se compone del «CAPÍTULO 3. El posicionamiento geopolítico de ELO en el ciberespacio", que se explaya en el caso de estudio en un sentido amplio abarcando una descripción de sus instituciones y sus prácticas. El capítulo tiene una división interna en dos apartados. En el primer apartado exponemos dos ejemplos de domiciliación nacional (Francia y Argentina) en los que estudiamos cómo la idea de Nación se materializó en acciones concretas de masificación de la vida comunitaria, en una relación de tensión y negociación sobre las significaciones de unificación nacional que dominaban las esferas políticas y culturales. Haciendo un ejercicio comparativo, en el segundo apartado se describe el caso de la tesis: Electronic Literature Organization (ELO). En la reposición de la historia que se desarrolla durante dos décadas encontramos la justificación de la elección del objeto ya que se trata de un caso pionero por su temprana formación, su alta institucionalización y su ampliación hacia zonas fuera del norte que lo dominaba en un principio. Mencionamos aquí brevemente que un criterio de selección que resultó central fue que además de incluir volúmenes de literatura de producción digital para ser generada y consumida exclusivamente en línea, tal como la define Hayles (2008) (y que deja fuera blogs, libros digitalizados, versiones digitales de literatura impresa), pudiera dar 
cuenta de otros aspectos del campo: autoría/coautoría, artistas, publicaciones, financiamiento, foros de interacción con el público lector, crítica, organización de eventos referidos a este tipo de literatura. Es decir, ELO es una organización que tiene por finalidad promover y financiar producciones de literatura digital en vistas a conformar una red mundial en la que intervengan cada uno de los agentes que construyen el campo. En este sentido se trata de un caso pionero ya que convoca una gran cantidad de obras sostenidas por un aparato comunicacional de amplia difusión, posibilitando el diálogo entre críticos, autores y público usuario a través de herramientas online que la misma organización provee sostenidamente a lo largo del tiempo.

Descriptas las características del caso, se exponen las distintas prácticas y espacios que se suceden en la organización y argumentamos en pos de una domiciliación no nacional sino interzonal, apelando a la teoría repuesta en los dos primeros capítulos de apertura de la tesis.

A continuación, se presenta la Segunda Parte: Tecnologías, donde se postula que, ante un nuevo contexto de emergencia de la cultura visual global (Darley, 2000), la literatura digital desarrolla su poética retomando un lineamiento marginal dentro del canon «nacional», el de la poesía visual (Bou, 2003; Funkhouser, 2007; Perednick, Doctorovich y Estévez, 2016), que se manifiesta en la crítica al soporte. De este modo, se elabora una genealogía que describe la transformación de soportes - de impreso a digital — hasta arribar a la literatura digital inscripta en un momento histórico en el que el componente visual tiene una posición dominante (Williams, 1977) en contraposición a lo que sucedía antaño (Cronin, 2017). El objetivo específico es construir una genealogía de las poéticas tecnológicas alojadas en ELO (vol. 1, 2, 3) vinculada a la poesía visual y el uso crítico del soporte material (impreso-digital), en el marco de cruce entre arte y tecnología.

Esta Segunda Parte se compone a su vez de dos capítulos que describen y explican el eje tecnologías en sus dos variantes: diacrónica — la genealogía en la que se inscribe la literatura digital—y sincrónica — la definición de esta literatura experimental nacida digital y consecuentemente, la metodología que se precisa para estudiarla en un nuevo contexto de producción y consumo-. Es dable notar aquí también que en esta parte de la tesis comienzan a aparecer imágenes que primero ilustran obras de poesía visual y son un apoyo para algunas descripciones que hacemos en el capítulo 4 y, posteriormente, se incluyen imágenes de obras (capturas de pantalla) que se analizan en el capítulo 5 y en toda la tercera parte de la tesis.

En el «CAPÍTULO 4. La poesía visual como raigambre de la literatura digital» se recupera una genealogía no exhaustiva, dada la exigua información con la que contamos, de la poesía visual, desde sus primeros desarrollos en la Antigüedad y la Edad Media, hasta los siglos XIX y XX en la que se profundiza esta variante y existe, además, mayor documentación disponible sobre la experimentación con la tecnología de la imprenta. Desde fines del siglo XIX y hasta después de la Segunda Guerra Mundial, los primeros «ismos» y luego las llamadas vanguardias históricas (Bürger, 1974) experimentan con «las palabras como dibujos» (Bou, 2003; Gómez, 2018) y el cruce entre literatura y artes visuales se hace estrecho y potente. Posteriormente, en un periodo posvanguardista y con la aparición de la electrónica, se pasa a una nueva fase de experimentación en donde las máquinas siguen promoviendo una relación entre arte y tecnología, pero ahora mediada por lenguajes de programación cada vez más omnipresentes. Finalmente, se llega a lo que hoy se conoce como literatura digital. Recuperando esta genealogía, el capítulo cierra con un apartado en donde se identifican los modos en que la tecnología de la palabra, es decir, el soporte material en donde se estampa la letra, negocia sus significaciones con domicilios 
políticos posibles. Así, una historia de la tecnología no debería carecer del aporte de las artes por las funciones potenciadoras y contextualizadoras que cumple en cada caso.

Vinculado con las reflexiones que cierran el capítulo 4, presentamos el «CAPÍTULO 5. Literatura y tecnología», en el que traemos a colación la relación entre la literatura y su soporte material en términos no solo de poéticas sino de política. Un primer y vasto apartado se dedica a conceptualizar la literatura digital siguiendo distintas aristas de posible definición, para un objeto que se escabulle en la fluidez propia del mundo contemporáneo.

Seguidamente se presenta un largo desarrollo metodológico para analizar las obras contenidas en los tres volúmenes alojados en el caso de estudio y que han sido ya descriptos, a grandes rasgos, en el capítulo 3. Al elegir este corpus, me encontré frente a una disyuntiva de difícil solución. El corpus tiene una gran amplitud, pero elegir otro tipo de plataforma de menor institucionalización e internacionalización que ELO me exponía a un riesgo que consideraba aún mayor: al trabajar con material digital, la caducidad propia del ciberespacio debilita la factibilidad del estudio por cuestiones de permanencia online que no podía prever. Por un lado, internet me permitía indagar de lleno en puntos inexplorados aún por la crítica. Pero su misma condición virtual nos ponía frente al problema de su posible desaparición temprana. De modo que decidí transitar el camino más firme en cuanto a la permanencia de las obras y su visibilización, y me quedé con el problema sobre la taxonomía que hiciera posible abarcar el tamaño del corpus de los volúmenes. En relación con ello, propongo un diseño de tres grandes lineamientos (sincrónicos) atravesados por tres generaciones (diacrónicas). Los lineamientos se establecieron a partir del encuentro de constantes que se transformaron en indicadores y cuya nomenclatura y justificación requirió un apartado completo y de mucha relevancia en el capítulo 5. De hecho, dio lugar a un trabajo para un congreso (IILI, Bogotá, Colombia, junio 2018), a su reestructuración en un Conversatorio con comentarista (Conversatorio de Tecnoestética, Córdoba, Argentina, marzo 2019), a su reelaboración y un artículo en ciernes (Dossier de Literatura Digital Latinoamericana para Revista Iberoamericana, Universidad de Pittsburg, EE. UU.).

Vinculado estrechamente con la metodología, existía una serie de problemáticas epistemológicas cruciales: por la propia naturaleza de aquello que pretendía investigar, indagamos sobre los procesos de transformación de categorías como «Nación», «lengua», «autor», en el marco de las producciones de literatura digital, con lo cual el recorte del objeto se realiza de manera no atada a criterios convencionales de selección, puesto que la exploración y disolución de dichas categorías tradicionales constituye una parte sustancial de la investigación en sí. El cambio tecnológico actual, desde esta perspectiva, desplaza el interés por la idea de Nación como forma neurálgica en la direccionalidad discursiva, sin por ello desprenderse de prácticas de producción y consumo de literatura que con ella se establecieron. Esto confluye en la necesidad de una reorganización epistémica de los saberes (Topuzian, 2017) y, consecuentemente, me interpelaba sobre criterios alternativos para asegurar la elección y la factibilidad del desarrollo de la investigación. De allí también el diseño metodológico específico que propuse en este capítulo.

Una vez definido el objeto de la tesis, la literatura digital, y el diseño metodológico, los apartados siguientes trabajan con las formas en que la literatura y la tecnología convergen y conviven en una relación crítica y reflexiva. ¿Cómo incide la tecnología en la vida de las formas literarias digitales? Para ello, se establece una diferencia entre técnica y tecnología, los mensajes políticos que se encarnan en la literatura digital, los vínculos entre literatura y discurso científico que 
surgen de la experimentación con máquinas y los desbordes disciplinares e institucionales de los que esta literatura es objeto - la robótica, la ingeniería, la programación, las ciencias de la comunicación, la filosofía, la filología, la traducción- Los apartados se desarrollarán teóricamente, remitiéndonos al capítulo 2 en donde definí la interzona, en conjunto con análisis de las obras que conforman los volúmenes e imágenes para dar al lector de la tesis una referencia.

Para cerrar la tesis, se presenta la Tercera Parte: Lenguajes. Allí la hipótesis subsidiaria sostiene que el vínculo lengua-literatura nacional se reformula en lenguajes inter/transmediales (Brillenburg, 2006; Rajewsky, 2005) y literaturas expandidas (Kozak, 2017b), configurando una nueva cartografía de institucionalización del campo y de relaciones de poder entre sus agentes. El objetivo específico es identificar las intervenciones glotopolíticas en el campo tecno-cultural (Romano Sued, 2012): de una lengua nacional verbal homogeneizadora a lenguajes inter/transmediales. Esta parte se compone de dos capítulos que se dedican a las formas en que políticamente el lenguaje modela la cultura. Y con lenguaje no solo me refiero al verbal sino también y, sobre todo, a los lenguajes inter y transmediales que dominan las obras estudiadas.

En el «CAPÍTULO 6. Cartografías glotopolíticas», reconstruimos la forma en que la lengua se asoció a la Nación de manera tal que conformó cierta organización política que modelaba la imaginación de un territorio nacional y, en consecuencia, de la comunidad de pertenencia. Ese surgimiento en Europa tuvo su reproducción en el mundo colonial no sin fisuras ni sin conflictos ya que, como señalan Deleuze y Guattari (1980), no se puede calcar una cartografía por su característica movilidad constitutiva. El positivismo decimonónico llevó al apogeo las teorías filológicas y biologicistas de la lengua y se establecieron lazos de parentesco, así como formaciones discursivas que apelaban a los vínculos entre la lengua y el lugar como «evidencias literarias». Y en paralelo, la masificación de la literatura impresa y del periódico permitió «narrar la Nación», cuestión trabajada previamente en el capítulo 1 de la tesis. De ese modo, retomando lo ya planteado en la primera parte de la investigación, exploramos las formas en que las lenguas verbales organizan sus glotopolíticas en el marco de instituciones y agencias del campo —editores, traductores, críticos, lectores—, cuyos faros opacan espacios emergentes o residuales. Esa organización propia de la modernidad retorna en la convivencia de obras en la interzona en la que se ubica la literatura digital de los volúmenes de ELO. Para cerrar el capítulo, se analiza una serie de obras que retoman determinados indicadores que se aferran a las lenguas verbales en competencia con lenguajes inter/transmediales.

El cierre de esta tercera parte es el «CAPÍTULO 7. Lenguajes en la interzona» en donde expongo más ampliamente la idea de que los lenguajes «interzonales» remiten a una tradición de poesía visual expuesta en el capítulo 4. Es decir, las palabras son miradas como dibujos (Bou, 2003; Gómez, 2018) y la interacción con las obras involucra una especie de traductibilidad expandida (Gómez, 2019) en la que ya no importa la Nación de procedencia ni, consecuentemente, la lengua en tanto que modeladora de una identidad nacional, sino que lo que posiciona a una obra tiene que ver con los recursos tecnológicos de los que se sirve y del lenguaje posibilitado mediante ellos — cinético, fotográfico, sonoro, performático, etc.- Se crea así una nueva subjetividad lectora, en tanto y en cuanto ya no hablamos de lector sino de usuario o lectoespectador (Escandell Montiel, 2012), al tiempo que se renuevan las alianzas y las disputas que configuran estas formas expandidas del lenguaje. 


\section{Toma 4. El flashback de los tropiezos}

En torno a los problemas que acontecieron a lo largo de la tesis, primordial y primeramente, el proceso de construcción categorial estuvo atravesado por un escollo frecuente: la dificultad de encontrar bibliografía en un campo de incipiente aparición como es el de la literatura digital en cruce con uno de larga data como es el de la teoría política. La idea de Nación en relación con una literatura impresa en lengua nacional es constitutiva del desarrollo de la modernidad y puede ser explicada desde su lugar de hegemonía que atraviesa una inmensidad de dominios no necesariamente con relación directa a uno u otro componente. Pero al acercarnos al dominio de la literatura digital resultaba dificultoso encontrar definiciones que permitieran explicar sin acudir a muchos otros campos, de qué se trataba. De allí que en el capítulo 4 se intenta mostrar la tradición de la poesía visual en la que se inscribe, una tradición de corte marginal a la hegemonía de la literatura impresa (y anteriores). Esa propia marginalidad también dificultó la búsqueda de bibliografía específica.

Otro problema que hallamos frecuentemente fue el de tener que «inventar» nomenclatura para aquello que aún no ha sido dicho. El hallazgo que parece más saliente es el de interzona, forma de nombrar el lugar de residencia en donde podemos pensar la nueva geopolítica mundial en relación con la literatura digital ya no nacional y que ocupa enteramente el capítulo 2 . Para mostrar cómo funciona este concepto, se presenta la propuesta de análisis de los capítulos 5, 6 y 7, cada uno con impronta propia. En este mismo sentido, como decía oportunamente, la construcción de un diseño metodológico acorde al objeto que estudiamos supuso pensar el recorte de corpus por fuera de las categorías ceñidas por la idea de Nación. Las razones están a la vista: pretendía mostrar que la idea de Nación en relación con la literatura sufre una corrosión de sus elementos constitutivos que provoca un cambio en la función de partida. Entonces se hizo necesario diseñar un aparato de lectura que permitiera clasificaciones adecuadas de la descripción de las obras.

También es dable mencionar que una de las razones más poderosas por las que elegí como caso ELO es debido a su alto nivel de institucionalización. Esta era la única forma de asegurarnos que los problemas de caducidad de experimentación con las obras no impidieran el desarrollo exitoso de este trabajo de largo aliento. Sin embargo, la caducidad de los softwares que se precisan para navegar el corpus se presentó en repetidas ocasiones. Dado que en muchos casos se trata de trabajos o proyectos realizados hace 20 o hasta 30 años, entonces pertenecen ya a un corpus canónico que ha quedado registrado emulando la experimentación en vídeos. Esos vídeos repusieron, en algunas ocasiones, los elementos necesarios para traer a colación referencias carentes de otra forma de visualización. Cuando esto fue imposible, tomé la decisión de no tenerlos en cuenta o de mencionarlos basada en la información procedimental que sí se encuentra en las breves entradas de la ELC o de otros proyectos asociados a ELO como Electronic Literature as a Model of Creativity and Innovation in Practice (ELMCIP) o Electronic Literature Directory (ELD). ${ }^{4}$

Esta investigación fue además posible porque muchas dudas documentales y muchos datos sobre la organización en su totalidad fueron obtenidos gracias a la generosa ayuda de los presidentes de la ELO: Dene Grigar (2013-2019) y Leonardo Flores (2019-presente). Ellos, junto con la comisión académica mostraron interés en mi trabajo y contestaron mis consultas en cada ocasión, lo que permitió una exhaustiva reconstrucción del campo que puede leerse en el capítulo 3. 


\section{Toma 5. El murmullo de lo inconcluso}

Volvamos al problema inicial: la relación entre literatura y lugar. Quise responder dónde se domicilia políticamente un tipo de escritura que tiene localización móvil, valga el oxímoron, dado que se inscribe en un espacio in-between, una interzona que combina elementos que no son propios de la modernidad, pero que no pueden deshacerse del todo de los nacionales. Mi tesis no propuso estudiar cuantitativamente la literatura digital ni los datos obtenidos en la reconstrucción del campo (vinculados a información de corte socioeconómico), pero en torno a esto último se podría pensar en una gradación entre obras más cercanas a problemáticas desprendidas de la construcción simbólica y de soberanía como es la idea moderna de Nación. En esta gradación reaparecen tanto las territorialidades como las tecnologías y los lenguajes, pero estas dimensiones deberían ser clasificadas a partir de estrategias de cuantificación de datos que permitieran observar el impacto de ciertos programas, géneros y distribución de los elementos.

La misma base de datos, construida a partir de una serie de decisiones epistemológicas y metodológicas, permitiría desarrollar un conjunto de visualizaciones tridimensionales e interactivas que podrían graficarse mediante software de mapping. Durante junio de 2019 y gracias a la obtención de una beca total de estudio provista por DHSI (Digital Humanities Summer Institute), realicé una escuela de verano intensiva en la Universidad de Victoria (BC, Canadá) en la que comencé a gestar la idea de utilizar esos datos para cartografiar las desigualdades en recursos y financiamiento que convocan un trabajo diferenciado de la literatura digital, sea en su circuito de producción, sea en su distribución, sea en su consumo. En esta distribución desigual se vuelve a observar la intromisión de elementos nacionales que obturan o posibilitan desarrollos vitales y artísticos.

Por otro lado, la exploración acerca de la relación entre literatura y lugar continúa siendo primordial, pero se refunda en nuevos intereses que aparecieron haciendo la investigación en sí misma. Un fuerte impulso me dirige hacia la literatura que se corporiza en máquinas, entre la carne y la piedra, como nos enseñó el libro de Richard Sennett (1996). De allí dos nuevas preocupaciones teóricas me alientan a seguir adelante. Por un lado, la traducción entre lenguajes intermediales, de donde deriva una pregunta incipiente propia de la contemporaneidad: ¿qué lengua hablan las máquinas en su reverso? Por otro lado, la migración de los cuerpos parlantes atravesados por máquinas de escritura: ¿qué relación existe entre traducción y migrancia? Cuerpos mediados inevitablemente por máquinas, obras que dicen esas mediaciones, lectores que realizan el laborioso intento de traducir esas poéticas tecnológicas. Estas cuestiones me ocuparon, al menos para la presentación de resultados iniciales, en el desarrollo de un proyecto financiado por una beca de posgrado otorgada por DAAD (Deutscher Akademischer Austauschdienst) y radicada en la Universidad de Frankfurt durante el semestre de otoño-invierno europeo de 2019-2020. En la misma Universidad y con una nueva financiación de la DAAD, de marzo a julio dictaré dos seminarios de grado, tendientes a la difusión de los temas de este trabajo de largo aliento aquí reseñado.

Por último, en el proyecto posdoctoral titulado «Formas migrantes de aparición del pasado en la literatura digital latinoamericana: memorias, soportes, traducciones, corporalidades» propongo llevar a cabo una investigación específicamente con un enfoque de corte más localizado en Latinoamérica. En particular, me detengo en algunas cuestiones que fueron advertidas por el jurado evaluador de la tesis en torno del giro archivístico en curso. Aquí trabajaré la relación entre literatura y lugar desde las migraciones de artistas, memorias nacionales y soportes escriturales. 
Este trabajo se complementa con una investigación colectiva de la que formo parte «Archives in Transition: Collective Memories and Subaltern Uses» financiado por la Unión Europea en el marco de la programación Horizon 2020.

\section{Coda: una pasión que no cesa}

Aquello que comenzó como un planteo venido de la teoría económica, una ecuación que a primera vista ofrecía una forma sintética de decir el problema, aparece ahora con las dificultades y los encuentros imprecisos que adquieren, afortunadamente, las investigaciones que migran, como sus investigadores, en el camino. Mi tesis invita a transportarse por conceptos, en el sentido etimológico de la palabra. Y es que transportar procede del latín trans y portare, llevar a otro lado, cambiar de lugar, una pasión que no cesa.

\section{Notas}

1 La tesis doctoral para optar por el título de doctora en Humanidades (Doctorado de Humanidades, FHUC-UNL) se titula «Domicilios de la literatura digital: de la idea de Nación a la de interzona en ELO (Electronic Literature Organization)», y se realizó bajo la dirección de la Dra. Analía Gerbaudo y la codirección de la Dra. Susana Romano Sued. Fue defendida satisfactoriamente el 28 de agosto de 2020. El jurado evaluador, compuesto por la Dra. Claudia Kozak (UBA-CONICET), el Dr. Juan José Mendoza (UBA-UNA) y la Dra. Isabel Molinas (UNL), recomendó la publicación, aún en ciernes.

2 Max Weber (2012) formula una interesante pregunta inicial en su célebre texto La ética protestante y el espíritu del capitalismo. Allí indaga sobre la relación entre una mentalidad económica particular — el capitalismo — con determinadas ideas religiosas - las del protestantismo-. Y señala el éxito que tuvieron en su vinculación ciertas ideas por sobre otras conviviendo en la época. En este caso, podríamos pensar en la idea de Nación como una idea exitosa de la modernidad, en relación con otras emergentes que no tuvieron la misma suerte.

3 En 2014, cuando estaba escribiendo mi tesis de Maestría (Gómez, 2015), comencé la carrera de Licenciatura en Ciencia Política en FHUC-UNL. Ese tránsito que se sostuvo hasta 2016 inclusive, año en que cursé la materia aquí mencionada, y que actualmente he retomado, me sirvió enormemente para mi formación en teoría política, en especial, y para redireccionar los conceptos hacia un cruce posible y novedoso entre Letras (mi carrera de base) y Ciencia Política.

4 Durante 2018 fui convocada para colaborar con una serie de reseñas críticas sobre literatura digital latinoamericana en ELD. Esa colaboración motivó una nueva convocatoria en 2019 como co-editora de un proyecto de reciente aparición llamado The Digital Review, publicación bianual de cuyo staff formo parte. Estas colaboraciones también ayudaron a que pudiera tener acceso a ciertos trabajos de artistas que conocí por intermedio de colegas académicos o incluso de otros artistas, con quienes se ha ido construyendo una extensa red a lo largo del tiempo.

\section{Referencias}

Anderson, B. (2006). Imagined Communities: Reflections on the Origin and Spread of Nationalism. Londres: Verso.

Appadurai, A. (2001). La modernidad desbordada. Dimensiones culturales de la globalización. México: Trilce/ Fondo de Cultura Económica.

Balibar, E. (1991). La forma nación: Historia e ideología. Raza, Nación y Clase (pp. 135-171). Madrid: IEPALA Textos.

Beiguelman, G. y La Ferla, J. (2011). Nomadismos Tecnológicos. Dispositivos móviles. Usos masivos y prácticas artísticas. Buenos Aires: Ariel/Fundación Telefónica.

Bou, E. (2003). II. Llegir dibuixos o mirar textos (Tradició de la poesía visual). La crisi de la paraula. Antología de la poesía visual. Barcelona: Edicions 62. 
Bourdieu, P. (2005). Las reglas del arte. Génesis y estructura del campo literario. Barcelona: Anagrama.

Brillenburg Wurth, K. (2006). Multimediality, Intermediality and Medially Complex Digital Poetry. RiLUnE,

(5), 1-18. http://www.rilune.org/images/mono5/3_brillenburg.pdf

Bürger, Peter (1974). Teoría de la vanguardia. Barcelona: Península.

Casanova, P. (2001). La República mundial de las Letras. Barcelona: Anagrama.

Chun, W. (2011). Nómades que imaginan. En Beiguelman, G. y La Ferla, J. Nomadismos tecnológicos. Dispositivos móviles. Usos masivos y prácticas artísticas (pp. 49-60). Buenos Aires: Fundación Telefónica/Ariel.

Cronin, S. (2017). Can we still speak of a «French» digital literature? ELO PORTO 2017 (pp. 1-21). Porto.

Darley, A. (2000). Cultura visual digital. Barcelona: Paidós.

Deleuze, G. y Guattari, F. (1980). Mille Plateaux. París: Les Editions de Minuit.

Derrida, J. (1997). Mal de archivo. Una impresión freudiana. Madrid: Trotta.

Escandell Montiel, D. (2012). Lectoautoría y colectividad en la narratología de la blogoficción. Congreso Iberoamericano de la Educación en las Lenguas y en las Culturas (pp. 1-12). IV Congreso lLeer.es. Salamanca: Universidad de Salamanca.

Febvre, L. y Henri-Jean, M. (1962). El mundillo del libro. La aparición del libro (pp. 136-170). Buenos Aires: Unión Tipográfica.

Funkhouser, C. (2007). Prehistoric digital Poetry. An Archealogy of forms, 1959-1995. Tuscaloosa: Alabama University Press.

Goldchluck, G. (2013). Nuevos domicilios para los archivos de siempre. El caso de los archivos digitales. Palabras de Archivo (pp. 35-57). Santa Fe: Ediciones UNL.

Gellner, E. (2001). Naciones y nacionalismos. Madrid: Alianza.

Gómez, V.(2015). Transformaciones y desplazamientos del guión museístico en torno a la idea de Nación. Un estudio comparativo entre el museo de arte moderno nacional presencial y el virtual. Tesis de Maestría. Universidad Nacional de Córdoba. Inédito.

Gómez, V.(2017). Lenguas migrantes y desvíos críticos en The 27th // El 27 de Eugenio Tiselli. Artelogie, (11), 1-13.

Gómez, V. (2018). Leer mirando. Elementos para la comprensión y el análisis de la literatura digital latinoamericana. Rassegna Iberística, 41(110), 283-298. http://edizionicafoscari.unive.it/it/edizioni/ riviste/rassegna-iberistica/2018/110/leer-mirando-elementos-para-la-comprension-y-el-an/

Gómez, V.(2019). Máquinas de (de)codificar. Expansiones de la traducción en la literatura digital latinoamericana. Perífrasis, 10(20), 94-116.

Gómez, V.(2021). Traducciones expandidas en territorios interzonales: la disemiNación de la poesía digital en el ciberespacio. En Malloi, A. y Mattoni, S. (coords.). La poesía como transterritorio. Colección Colectivo Crítico. Universidad Nacional de La Plata. En prensa.

Hayles, K. (2002). Writing Machines. Cambridge/Londres: The MIT Press.

Hayles, K. (2008). Electronic Literature. New Horizont for the Literary. Indiana: University of Notre Dame.

Kozak, C. (Comp.) (2015). Tecnopoéticas argentinas. Archivo blando de arte y tecnología (2da edición). Buenos Aires: Caja Negra.

Kozak, C. (2017a). Latin American Electronic Literature: When, Where and Why. En Mencia, M. \#WomenTechLit (pp. 55-72). Morgantown: West Virginia University Press.

Kozak, C. (2017b). Literatura expandida en el dominio digital. El taco en la brea, (6), 220-245.

Maffesoli, M. (2006). Du nomadisme. Vagabondages initiatiques. La Table Ronde.

Molas, J. y Bou, E. (2003). La crisi de la paraula. Antologia de la poesia visual. Barcelona: Editions 62. 
Perednick, J.S.; Doctorovich, F. y Estévez, C. (2016). El punto ciego. Antología de la poesía visual argentina de 7000 a.C. al Tercer Mundo. San Diego: SDSU Press.

Portinaro, P.P. (2003). El mito del poder absoluto. Estado (pp. 53-69). Buenos Aires: Nueva Visión.

Rajewsky, I. (2005). Intermediality, Intertextuallity and Remediation: A Literary Perspective on Intermediality. Intermédialités, (6), 43-64. http://cri.histart.umontreal.ca/cri/fr/intermedialites/p6/pdfs/ p6_rajewsky_text.pdf

Rettberg, S. (2012). Developing an Identity for the Field of Electronic Literature. Reflections on the Electronic Literature Organization Archives. Dichtung Digital. http://www.dichtung-digital.org/2012/41/ rettberg.htm

Romano Sued, S. (1997). El espacio artístico y las metamorfosis estéticas: reflexiones en torno a las tecnologías, a la tecnocultura y a los espacios contemporáneos de arte. ETC, 27-38.

Romano Sued, S. (2012). La expoesía. Una perspectiva ética y política de los procesos artísticos. Tropelías. Revista de Teoría de la Literatura y Literatura Comparada Contemporáneos. Expoéticas Argentinas y sus contextos, (18), 104-117.

Romano Sued, S. (2013). Estética y Subjetividad en la Era Tecnoglobal. Problemas Actuales de la Estética. Babel. Sin rango de páginas.

Sennett, R. (1996). Flesh and Stone. The Body and the City in Western Civilization. Nueva York/Londres: Norton \& Company Inc.

Topuzian, M. (2017). Tras la nación. Conjeturas y controversias sobre las literaturas nacionales y mundiales. Buenos Aires: Eudeba.

Weber, M. (2012). La ética protestante y el espíritu del capitalismo. Madrid: Alianza.

Weber, M. (2015). Economía y Sociedad. México: Fondo de Cultura Económica.

Williams, R. (1977). Marxismo y Literatura. Barcelona: Península. 